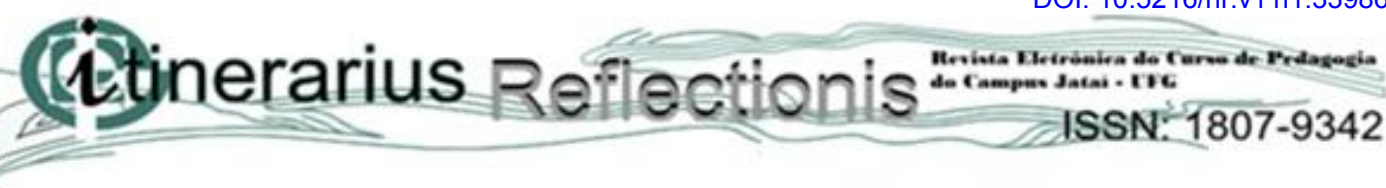

v.11, n. 1,2015

\title{
UM OLHAR SOBRE O ENSINO DE GEOGRAFIA: CONCEPÇÕES DE ALUNOS, PROFESSORES E GESTORES NO ENSINO FUNDAMENTAL ANOS FINAIS EM UMA UNIDADE ESCOLAR NO MUNICÍPIO DE FORMOSA GOIÁS
}

\author{
Marcos Vinicius Santos Dourado ${ }^{1}$ \\ Elton Souza Oliveira ${ }^{2}$ \\ João Gabriel Gomes ${ }^{3}$
}

\begin{abstract}
RESUMO: Diante das práticas de ensino/aprendizagem e a busca de um melhor entendimento da realidade escolar este trabalho busca evidenciar quais e como são as práticas de ensino em Geografia na modalidade do Ensino Fundamental, Anos Finais. Para tanto foi escolhida aleatoriamente uma escola da rede municipal de ensino, localizada geograficamente ao centro urbano da cidade de Formosa (GO). Como instrumentos metodológicos foram utilizados questionários dirigidos aos professores de Geografia, alunos e gestores com o intuito de investigar as concepções acerca do ensino de Geografia bem como a importância qual lhe é dada no cenário educacional do ano letivo de 2014. Foram entrevistados, diante de uma meta estatística e grupo amostral entre $17 \%$ a $20 \%$ do total de alunos da unidade de ensino escolhida, fazendo-se assim uma média geral sempre privilegiando os aspectos qualitativos, além dos dois professores de Geografia e da coordenadora geral do Ensino Fundamental Anos Finais da Secretaria Municipal de Educação de Formosa (GO). Os resultados obtidos demonstram que o Ensino de Geografia tem tido bons resultados qualitativos. Ao se observar as respostas, se teve uma visão positiva da prática de ensino/aprendizagem tanto na perspectiva dos alunos como dos professores, o único adentro a ser feito é a concepção da importância do Ensino de Geografia pelo grupo gestor do munícipio que parece um tanto longínquo da realidade escolar.
\end{abstract}

Palavras-Chave: Ensino. Aprendizagem. Geografia.

ABSTRACT: Given the teaching/learning practices and the quest for a better understanding of school reality this work seeks to evidence what are the teaching practices in Geography in the form of elementary school, Final Years, and how they work. For that was randomly chosen a municipal school located geographically in downtown of Formosa (GO). As methodological instruments, there were used questionnaires directed to Geography teachers, students and managers in order to investigate the conceptions of Geography teaching as its importance which is given in the educational scenario on the school year of 2014. Were interviewed in accord of a statistical goal and sampling group between $17 \%$ to $20 \%$ of selected students from the chosen unit, making itself an overall average, always giving

\footnotetext{
${ }^{1}$ Professor Efetivo da Rede Estadual de Ensino de Goiás e da Rede Municipal de Ensino de Formosa/GO. Email: mvsd82@gmail.com;

${ }_{2}^{2}$ Mestrando em Geociências Aplicadas com ênfase em Geoprocessamento e Análise Ambiental pela Universidade de Brasília. Email: elton.gea@gmail.com;

${ }^{3}$ Graduando do 4 ano/7 semestre no curso de Geografia pela Universidade Estadual de Goiás (UEG). Email: Gabriel.gms.fsa@gmail.com
} 


$$
\text { v.11, n. } 1,2015
$$

priority to the qualitative aspects, in an addition of two teachers of Geography and general coordinator of the Elementary School Final Years of the Municipal Office Formosa (GO) Education. The results obtained manifest that the Geography Teaching has had good qualitative outcome. By observing the answers, it had a positive view of the practice of teaching/learning both in the perspective of teachers and students, however the conception of the importance of Geography Teaching by the municipality manager group that appears somewhat far from the school reality.

Keywords: Teaching. Learning. Geography.

\section{INTRODUÇÃO}

Muito tem si discutido sobre as possibilidades, alternativas e caminhos do ensino da Geografia, principalmente a Geografia Escolar, vários autores como: (CALLAI, 2005; CASTROGIOVANNI, 1999, 2000, 2003; CAVALCANTI 1998, 2001，2003， 2012; KAERCHER, 1999; VESENTINI, 2004); tem ampliado nossos horizontes em relação ao ensino da Geografia, principalmente nas últimas duas décadas se teve um avanço enorme no que tange o ensino da geografia e suas propostas.

Esse trabalho tem sua importância para verificar como anda o ensino da Geografia na escolarização básica, mais especificamente no ensino Fundamental II, anos finais, que abrange do $6^{\circ}$ ao $9^{\circ}$ ano, para assim termos uma ideia de como tem sido trabalhado a Geografia Escolar pelos professores e como são as concepções dos atores envolvidos no processo de ensino/aprendizagem de forma direta, no caso, professores, gestores e alunos, assim objetiva-se captar tais concepções.

Como metodologia, foi utilizada a entrevista baseada em roteiro e questionários, sendo aplicado Termo de Consentimento Livre e esclarecido conforme Resolução CNS 196/96, com questões abertas e fechadas para qualificar e quantificar os dados demonstrando assim o cenário mais próximo possível da realidade do ensino ali praticado.

Foi escolhida por questões geográficas relacionadas à localização e a facilidade do acesso, sendo proporcionada uma clientela diversificada em relação a classe social a Escola Municipal Professor Joaquim Moreira que faz parte do sistema municipal de Ensino da cidade de Formosa (GO).

Foi um trabalho surpreendente, pois foi visto e corroborado com os dados que o ensino de Geografia vai muito bem, com professores participativos e com boa relação com os alunos 


\section{(t)innerarius \\ 2 \\ eirbeita de Car \\ ISSN:-1807-9342}

\section{v.11, n. 1,2015}

que demonstraram via entrevista bom retorno de informações das práticas de ensino e aprendizagem em Geografia apresentada por seus professores. Único adentro seria a concepção dos gestores da educação, na figura da coordenação geral do Ensino Fundamental no munícipio que não mostrou uma visão de acordo com o que vem sendo praticado na rede de ensino de sua responsabilidade.

Estruturalmente a pesquisa está dividida em um primeiro momento um levantamento referencial básico sobre os Parâmetros Curriculares Nacionais e o Ensino de Geografia, em seguida uma ilustração sobre a área estudada: a Escola Municipal Professor Joaquim Moreira e sua cidade: Formosa (GO), de forma simples e direta. Posteriormente apresenta-se a pesquisa, demonstrando os dados colhidos paralelamente à análise dos dados série a série e por fim as considerações finais.

\section{PARÂMETROS CURRICULARES NACIONAIS}

Segundo a SECRETARIA DE EDUCAÇÃO FUNDAMENTAL (1997), os PCN's Parâmetros Curriculares Nacionais, referem à renovação e reelaboração da proposta curricular, para reforçar a importância que existe em cada escola formular seu projeto educacional, e divulgar para toda a equipe. Para que as melhorias alcançadas na qualidade educacional resultem na busca entre todos os profissionais da educação. Afirma também, que a forma mais eficaz de elaboração e desenvolvimento de projetos educacionais é através do debate em grupo e no local de trabalho.

Os parâmetros curriculares nacionais buscam ajudar os professores nessa tarefa, de assumir como profissional as suas responsabilidades. Que os mesmos possam ser reconhecidos como peça fundamental no processo de formação do povo brasileiro.

Segundo a SECRETARIA DA EDUCAÇÃO FUNDAMENTAL (1997), os PCN's têm como função orientar e garantir a coerência dos investimentos no sistema educacional. Devem-se socializar discussões, pesquisas e recomendações, subsidiando a participação de técnicos e professores brasileiros, principalmente daqueles que se encontram mais isolados, com menor contato com a produção pedagógica atual.

Isso ajuda para que as diversidades culturais, regionais, étnicas, religiosas e politicas, sejam respeitadas, pois vivemos em uma sociedade múltipla, estratificada e complexa, e que 


\section{(4tinerarius 20

$$
\text { v.11, n. } 1,2015
$$

devemos fazer com que a educação possa atuar, decisivamente, no processo de construção da cidadania.

E visto que na busca de qualidade é necessário investimentos em diferentes áreas, como na formação inicial e continuada de professores, uma política de salários dignos, um plano de carreira, a qualidade do livro didático, de recursos televisivos e de multimídia, a disponibilidade de materiais didáticos. Mas esta qualificação almejada implica colocar também, no centro do debate, as atividades escolares de ensino e aprendizagem e a questão curricular como de inegável importância para a política educacional da nação brasileira.

Sabe-se que existe, diferenças, culturais, sociais, religiosas entre outras em cada região do país, e o PCN,s têm a função de tentar amenizar essas diferenças, igualando as formas de ensino, até mesmo para as populações que se encontrarem mais isoladas em algumas regiões brasileiras.

Cabe ao professor auxiliar para que se busque o consenso em utilizar as melhores formas de lidar com o ensino, através das melhores técnicas e formas de aprendizagem executadas.

\subsection{Parâmetros Curriculares Nacionais de Geografia}

Segundo a SECRETARIA DE EDUCAÇÃO FUNDAMENTAL (2001), o papel principal da Geografia, na proposta dos Parâmetros Curriculares Nacionais, se refere à compreensão e intervenção na realidade social. Por meio dela podemos compreender como diferentes sociedades interagem com a natureza na construção de seu espaço, as características dos lugares, as múltiplas relações de um lugar para outro, distâncias, diferenciação do espaço no passado e no presente.

De acordo VESENTINI, 2009, a escola deve se preocupar com a cidadania ativa, deve se preocupar com incentivar a formação de indivíduos que pensem por conta própria que aprendam determinadas competências, habilidades e inteligências múltiplas apropriadas para uma sociedade democrática e diversificada.

CALLAI (2013) aborda que os conteúdos de geografia são importantes, pois permitem estabelecer a sua especificidade e marcar o seu diferencial em relação às demais áreas do conhecimento. A geografia escolar assume um papel significativo no contexto do currículo da escola básica e se desenvolve nos objetivos do seu processo de ensino. 


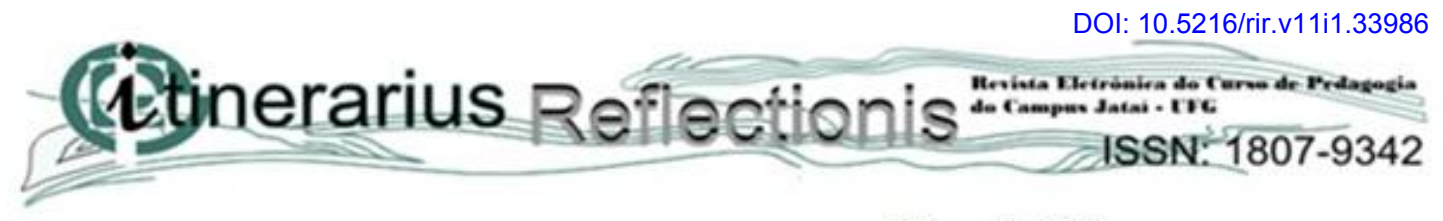

$$
\text { v.11, n. } 1,2015
$$

Segundo CAVALCANTI (2012), a Escola é um lugar de encontro de culturas, de saberes formais e informais, do cotidiano. A Escola lida com o cotidiano e a cultura, seja no interior da sala de aula, seja, nos outros espaços escolares, a geografia escolar é uma das mediações pelas quais o encontro e o confronto entre culturas devem acontecer.

Objetiva também que um aluno do ensino fundamental, consiga observar, conhecer, explicar, comparar e representar as características de um determinado lugar em diferentes espaços geográficos.

\subsection{A Escola Municipal Professor Joaquim Moreira}

A Escola Municipal Professor Joaquim Moreira (Figura 01) é uma instituição pública de ensino que atua nas modalidades de Ensino Fundamental I e II e com a Educação de Jovens e Adultos - EJA, $2^{\circ}$ segmento. Situa-se a Av. João Isper Gebrim, s/no , Bairro Formosinha.

Segundo seu Projeto Político Pedagógico, (PPP, 2014), a Escola Municipal Professor Joaquim Moreira segue uma proposta metodológica e filosófica que visa o desenvolvimento de propostas que atendam aos reais interesses e necessidades da sua clientela, buscando sempre implementar mudanças significativas na realidade escolar. Deste modo, os princípios filosóficos desta Unidade Escolar fundamentam-se na perspectiva da educação para a cidadania, visando contemplar os objetivos e diretrizes apontados pela Lei de Diretrizes e Bases da Educação Nacional 9.394/96, cuja finalidade máxima é desenvolver o educando, assegurando-lhe a formação indispensável para o exercício da cidadania e fornecer-lhe condições para atuar de forma crítica, consciente, participativa e responsável no meio em que vive. 


\section{(tetinerarius Refloctionis 2

$$
\text { v.11, n. } 1,2015
$$

Figura 01: Localização da Escola Municipal Prof ${ }^{\circ}$ Joaquim Moreira.

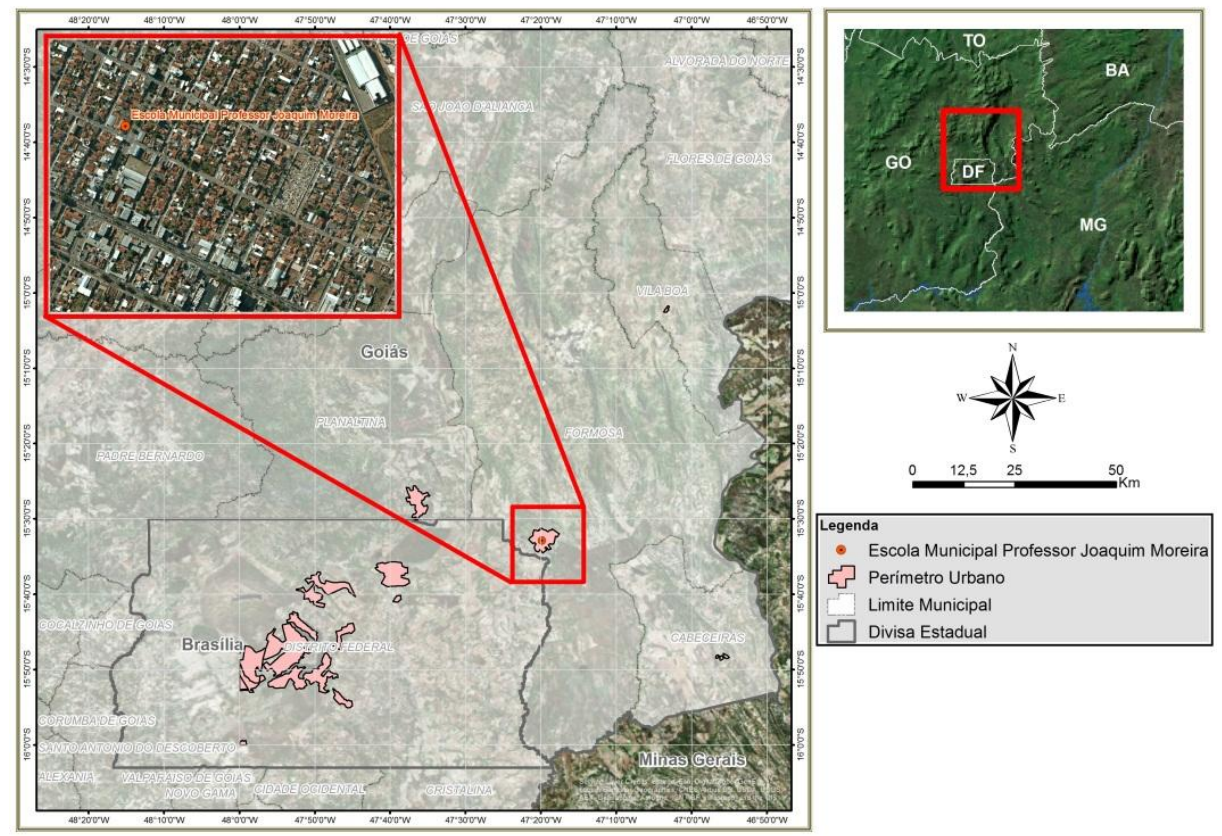

Fonte: OLIVEIRA, Elton S., 2015.

\section{ASPECTOS SOBRE A METODOLOGIA UTILIZADA}

A pesquisa teve um caráter investigativo à luz do método qualitativo, tendo em vista a familiarização dos autores com o objeto de estudo, desenvolveu-se através de levantamento do referencial bibliográfico, enriquecido com discussão em torno do objeto. Coleta de dados e informações por meio de pesquisa exploratória através de aplicação de questionários, que segundo Gil 1991 citado por KAUARK (2010) é uma pesquisa que busca uma familiaridade com o objeto, envolvendo levantamento de bibliografia, entrevistas com pessoas que tiveram algum tipo de experiência com o problema pesquisado, analisando exemplos para a compreensão. Buscando as três concepções sobre o ensino de geografia: o gestor, o professor e o aluno. Para tanto, foram elaborados três propostas de questionários semiestruturados, de modo que as questões gerassem informações fundamentais as quais norteiam à temática e pudesse enriquecer a discussão. Possibilitando assim, através destas informações e indagações, os autores fazerem uma reflexão acerca da vivência do aluno, com o que é ensinado e a visão da gestão educacional, para que assim pudessem tecer um paralelo do que é ensinado com o olhar do aluno em relação à Geografia. 


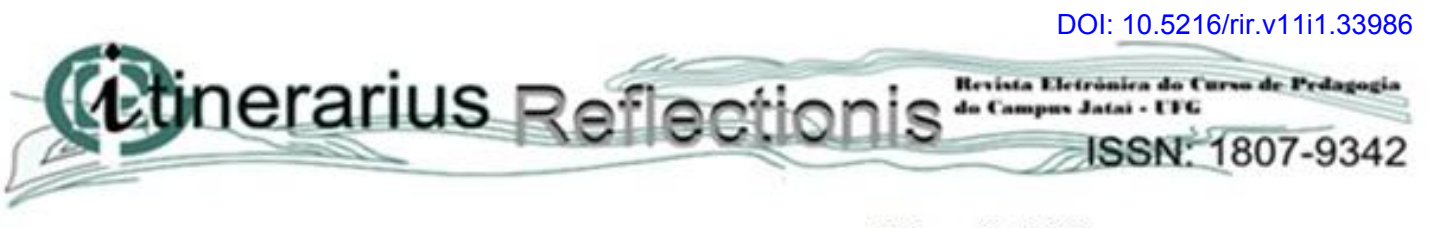

$$
\text { v.11, n. } 1,2015
$$

Foram aplicados questionários com os alunos, selecionados aleatoriamente em uma porcentagem de $17 \%$ a $20 \%$ de cada turma, com o intuito de captar com o máximo de sobriedade possível as diversas visões dos alunos com a Geografia, a pesquisa ocorreu no mês de Junho de 2014 em uma escola da rede municipal do perímetro urbano de Formosa (GO), a abordagem trabalha com escolarização básica, especificamente com ensino fundamental II, na disciplina de Geografia, onde estes docentes proporcionam o conhecimento básico para os alunos, todavia, o alcance e a fixação do conhecimento advêm do dia-a-dia dos discentes, com a teoria em sala, observação e até a prática do conteúdo abordado fora dela, tendo em vista que a visão dos alunos, dos professores e dos gestores que regem a educação municipal dá o entendimento de como ocorre o atual processo de ensino aprendizagem na ciência geográfica do município de Formosa (GO).

\section{O OLHAR DO GESTOR}

Foi elaborado, conforme a metodologia proposta, um questionário a ser aplicado na Secretaria Municipal de Educação com o intuito de perceber a visão da coordenação pedagógica a respeito do Ensino de Geografia no Ensino Fundamental.

A época a coordenadora possuía idade de 50 anos, com formação em Geografia atuando a mais de 20 anos como professora. Sobre quais as principais ações da equipe pedagógica desempenhadas no Ensino Fundamental, afirma-se que são realizados programas, eventos em datas comemorativas, simulados (provinha Brasil), Feira de Ciências e o Programa Mais Educação.

A respeito do acompanhamento da aplicação dos PCN's em relação ao planejamento das escolas municipais, foi explicitado que é feito um acompanhamento nas escolas de forma próxima, com visitas locais, além de ações em parceria com a SME no que tange o trabalho com temas transversais.

Questionada sobre o incentivo a formação continuada pela Secretaria de Educação, a coordenadora respondeu que a Secretaria "Oferece Formação Continuada em diversos temas para debates, Oportuniza Fórum Municipal de educação, visando à reflexão sobre as Políticas Educacionais municipais, estaduais e nacionais". A respeito da valorização dos profissionais ela, afirmou que o Plano de Cargos e Salários do Magistério está sendo reformulado, tendo 


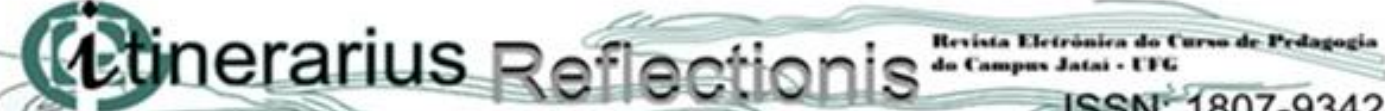 2

$$
\text { v.11, n. } 1,2015
$$

discussões e debates com diversos setores da sociedade, como o legislativo, executivo, o sindicato dos profissionais da educação e os próprios professores.

Sobre o trabalho específico direcionado ao ensino de Geografia, a coordenadora ressalta que são trabalhados vários projetos. Sobre a importância do ensino de Geografia na educação básica, a coordenadora afirma que o ensino de geografia na educação básica é a melhor possível, procurando parcerias (Syngenta, Pioneer, Embrapa). Sempre procurando incentivo governamental a e o ensino interdisciplinar, como exemplo, os projeto Agrinho SENAR/FAEG ${ }^{4}$ e Projeto Horta Orgânica FNDE ${ }^{5}$.

Existe um espaço entre respostas, onde não há especificamente o detalhamento do que realmente é feito, não demonstrando de forma clara as politicas de ação e valorização do ensino de Geografia no Ensino Fundamental II.

\subsection{Os Professores: Valorização do Cotidiano?}

Foram entrevistados os dois professores de Geografia da Escola estudada, sendo um homem e outra mulher, com idade de 30 e 42 anos respectivamente, com formações em Geografia e Pedagogia, variando o tempo de atuação entre 2 e 4 anos.

Quando perguntados sobre a visão destes sobre o que seria cotidiano e a possibilidade de se trabalhar no âmbito geográfico, ambos abordaram que são as atividades do dia a dia e que sim o conteúdo didático tem uma ligação com as atividades e vivências do aluno e do lugar em que vive.

Os professores afirmam utilizar o cotidiano geográfico como contexto em suas aulas, utilizando de pesquisa de campo e contextualizando informações, além de fazer uma sondagem d do cotidiano de cada aluno.

\footnotetext{
${ }^{4}$ Agrinho é o maior programa de responsabilidade social do Sistema FAEP, resultado da parceria entre o SENAR, FAEP, mediante as Secretarias de Estado da Educação, da Justiça e da Cidadania, do Meio Ambiente e Recursos Hídricos, da Agricultura e do Abastecimento, Criado com o objetivo de levar informações sobre saúde e segurança pessoal e ambiental, principalmente às crianças do meio rural, o Programa se consolida como instrumento eficiente na operacionalização de temáticas de relevância social da contemporaneidade dentro dos currículos escolares.

${ }^{5}$ O Projeto "Educando com a Horta Escolar (FNDE)" promove curso de 160 horas, para a formação de multiplicadores em estados e municípios. O objetivo do programa é usar a horta e a gastronomia como eixos geradores da prática pedagógica e para promover hábitos alimentares saudáveis, a valorização de ingredientes e receitas regionais e técnicas de preparo de alimentos.
} 


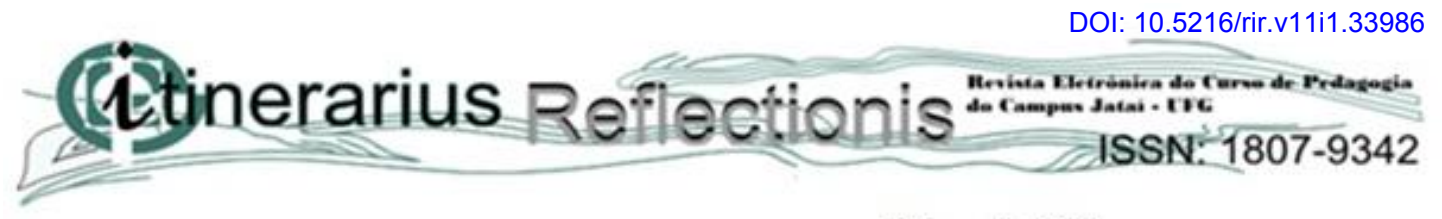

$$
\text { v.11, n. } 1,2015
$$

Foi perguntado aos professores sobre os conhecimentos e as vivências dos alunos, no caso, se eles acreditam que eles têm esse conhecimento, de acordo com as respostas todos tem sim, e que eles levam em consideração para a abordagem em sua prática de sala de aula.

Sobre a possibilidade de se trabalhar as vivências dos alunos na práxis geográfica, ambos abordaram que sim, e que esta vivência tem contribuindo para o aprendizado de todos os alunos, onde cada um traz viveres, experiências e mundos diferentes.

\subsection{Alunos do $6^{\circ}$ ano: A surpreendente professora}

Foram aplicados questionários aos alunos também, com o intuito de perceber através dos alunos como é realizado o trabalho do processo de ensino-aprendizagem em Geografia na Escola Municipal Professor Joaquim Moreira. Em relação à visão dos alunos sobre o ensino da Geografia, considera-se positivo, pois ao observar os questionários notou-se uma boa maturidade nas respostas. Em relação ao conteúdo programático ele está condizente com a série, fato demonstrado nas respostas dos alunos, exemplificando conteúdos tais como: localização geográfica, fusos horários, mapas e sua utilização, as categorias de análise da geografia: Paisagem, Espaço e Região.

Cabe destacar a surpreendente ação da professora que não é formada em Geografia, esta formada em Pedagogia, é relevante destacar o desempenho dos alunos que ao comparar com o desempenho de outras turmas do $6^{\circ}$ ano que são de responsabilidade de um professor de Geografia, estão em um mesmo patamar de conhecimento, mostrando um equilíbrio entre as variadas turmas.

Há alguns aspectos a se destacar sobre a interação onde alguns alunos demonstraram gostar mais da matéria em si do que do professor.

Em relação às competências e habilidades exigidas para o $6^{\circ}$ ano é evidente que este grupo está em um bom desenvolvimento acompanhando e absorvendo conteúdo de forma equilibrada e coerente com os propostos pelos parâmetros curriculares Nacionais.

\subsection{Alunos do $7^{\circ}$ ano: diversidade de conteúdos}

Nota-se nas respostas dos alunos que estes estão tendo um bom trabalho na perspectiva do ensino e aprendizagem com os professores, fato demonstrado nas respostas 


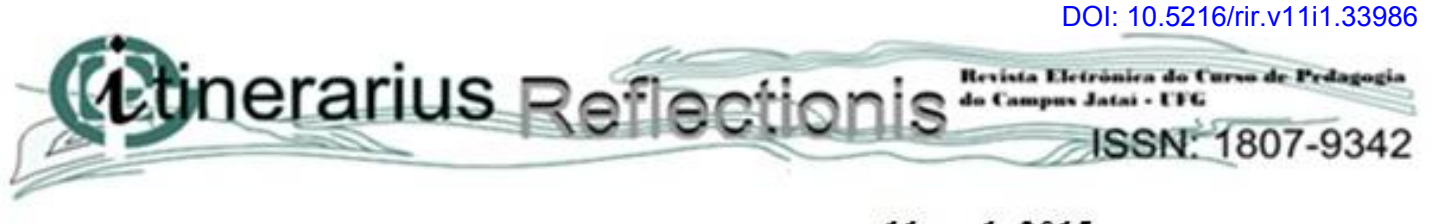

$$
\text { v.11, n. } 1,2015
$$

sobre os conteúdos estudados onde em um primeiro momento se teve uma grande quantidade de destaque sobre os Biomas Brasileiros, na segunda metade notou-se que o conteúdo de industrialização, artesanato, indústria de bens e consumo ganharam um maior destaque, cabe analisar e ver quais são os professores para verificar o porquê de tais citações e os que levaram a esse destaque.

Em relação ainda aos conteúdos citados notou-se uma variedade maior em relação ao $6^{\circ}$ ano, solos, industrialização, mapas, universo, desigualdade social, biomas, mostrando que o trabalho foi bem diversificado e que estes conseguiram ao menos identificar uma maior quantidade de conteúdos trabalhados durante o semestre.

Cabe salientar o bom relacionamento e interação entre professores e alunos, onde vários alunos elogiaram as atividades e o modo como se dão as aulas, com elogios como "o professor é divertido", "traz atividades diferentes", demonstrando que os professores estão buscando formas diferentes de se trabalhar além da mesmice da reprodução do conteúdo no cotidiano de sala de aula.

É relevante destacar o perfil de criticidade desenvolvido em sala de aula, onde vários alunos destacaram a importância social do conhecimento em Geografia na sua formação como cidadão.

\subsection{Alunos do $8^{\circ}$ ano: A prática e a influência do Enciclopedismo}

Em relação aos conteúdos citados foram observados que tivemos uma maior ênfase de citações em referência aos continentes e suas regionalizações, América Latina, África, também foi observado uma prática fortemente influenciada pelo enciclopedismo, haja vista a gama de citações em referência a biomas, terra, oceanos, florestas, natureza.

\footnotetext{
O Enciclopedismo não é específico da Geografia e atinge todas as disciplinas [...] A geografia se constitui como ciência quando ela entra na segunda metade do século passado no circuito da instituição universitária [...] O enciclopedismo da geografia escolar se centra mais sobre a precisão do detalhe (diferenciação das camadas geológicas, gênese das formas estruturais, nomenclatura ampliada para o "humano") que sobre a totalidade dos fenômenos geográficos, (OLIVEIRA, 2012, p.19).
}

Cabe destacar que os alunos tiveram uma maior dificuldade de se expressar durante os questionários com respostas com vários sentidos, às vezes contraditórios. 


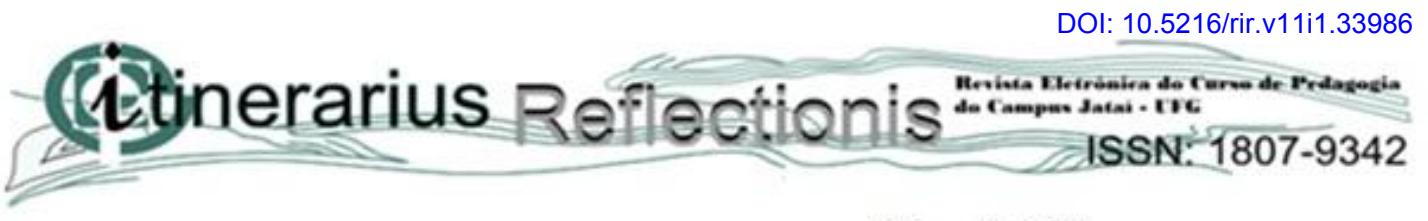

$$
\text { v.11, n. } 1,2015
$$

Foram levantadas pelos alunos as aulas diferenciadas praticadas pelo professor, tendo em vista que vários alunos citaram que saíram de sala de aula, que o professor passa atividades diferenciadas e divertidas.

Vale salientar que esta série foi a que teve um maior índice de rejeição em relação à Geografia.

\subsection{Alunos do $9^{\circ}$ ano: a experiência e o fim de ciclo}

Percebe-se uma grande participação do professor em meio aos elogios a sua pratica pedagógica, tais como dinâmicas, atividades diferenciadas (saída de campo, aluas no laboratório de informática, passeios). O conteúdo que foi bastante destacado foi o de globalização. Também vale salientar que foram citados conteúdos na parte em que se questiona o que vem a mente quando se fala em Geografia, referências do 6 e $7^{\circ}$ ano, mostrando que boa parte dos conteúdos trabalhados em séries anteriores foram internalizados, demonstrando uma boa sequência didática e a prática das competências e habilidades dos alunos durante o ensino fundamental $2^{\circ}$ ciclo.

Cabe destacar também o excesso de visão histórica dentro do ensino geográfico, que é importante, porém não pode se tornar uma visão única o que caracteriza outra disciplina, no caso História, tirando a identidade da Ciência Geográfica.

Vale ressaltar que não houve reclamações e nem respostas negativas em relação ao gosto pela matéria.

\section{CONSIDERAÇÕES FINAIS}

Diante do objetivo inicial deste trabalho, verifica-se que o ensino de Geografia praticado na Escola Municipal Professor Joaquim Moreira está de acordo com o promulgado pelos PCN's, onde os professores procuram valorizar o conhecimento prévio, o mundo vivido dos alunos, propondo atividades variadas e diferenciadas, notou-se também que os alunos também tem uma boa relação com os professores, afirmativa evidenciada nas respostas durante as entrevista.

Os alunos apresentaram também uma boa noção do que seria a Geografia enquanto ciência, mostrando que os professores também tiveram sucesso em situá-los sobre as 


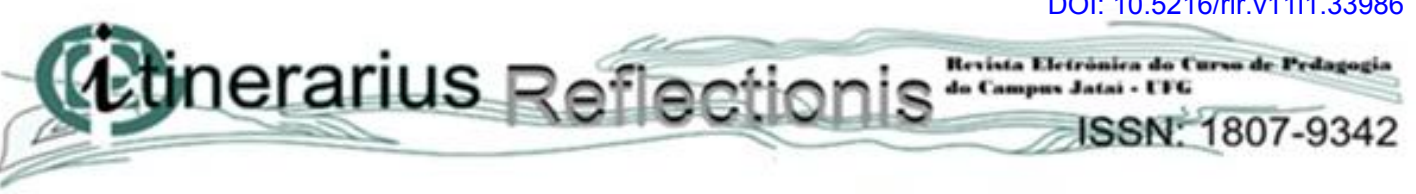

$$
\text { v.11, n. } 1,2015
$$

características da disciplina, onde eles, alunos, conseguiam situar bem os conteúdos por eles estudados.

Já a Gestão apresentou um olhar um pouco distante da realidade do ensino de Geografia com respostas vagas em relação à prática pedagógica das escolas necessitando uma aproximação no que tange o ensino das disciplinas no nível fundamental, anos finais.

\section{REFERÊNCIAS BIBLIOGRÁFICAS}

CALLAI, Helena Copetti, Aprendendo a ler o mundo: A Geografia nos anos iniciais do ensino fundamental. Cad. CEDES, Campinas, vol. 25, n. 66, p. 227-247, 2005.

Unijuí, 2013.

Helena Copetti, A formação do professor da geografia: O professor, Ijuí - RS, Ed.

CASTROGIOVAni, Antônio Carlos. et al. (org.) Geografia em sala de aula: práticas e reflexões. 4. ed. Porto Alegre: editora da UFRGS, 1999.

, Antônio Carlos. et al. (org.) Geografia em sala de aula: práticas e reflexões. 4. ed. Porto Alegre: editora da UFRGS, 2003.

CAVALCANTI, Lana de Souza, Geografia, escola e construção de conhecimento: Geografia e a construção de conceitos no ensino. Campinas, SP: Papirus, 1998.

Papirus, 2001.

Lana de Souza. Geografia, Escola e construção de conhecimento. São Paulo:

Lana de Souza, A Geografia Escolar e a cidade: Ensaios de Geografia para a vida urbana cotidiana. Campinas, SP: Papirus, 2012.

Papirus, 2012.

, Lana de Souza, O Ensino de Geografia na Escola, Campinas, São Paulo,

KAERCHER, Nestor André et al. A Geografia no ensino médio. In: CASTROGIOVANI, Antônio Carlos. et al. (org.). Geografia em sala de aula: práticas e reflexões. 4. ed. Porto Alegre: editora da UFRGS, 1999.

KAUARK, Fabiana. Metodologia da pesquisa: Guia Prático / Fabiana Kauark, Fernanda Castro Manhães e Carlos Henrique Medeiros. - Itabuna : Via Litterarum, 2010.

OLIVEIRA, Ariovaldo Umbelino de, Para onde vai o Ensino de Geografia? (org.), $10^{\mathrm{a}} \mathrm{Ed}$. - São Paulo: Contexto, 2012.

PPP, Projeto Politico Pedagógico, Escola Municipal Professor Joaquim Moreira, Formosa Goiás, 2014. 


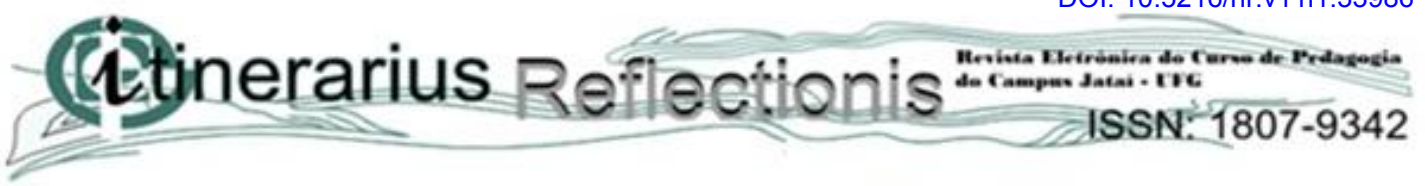

$$
\text { v.11, n. } 1,2015
$$

SECRETARIA DA EDUCAÇÃO FUNAMENTAL. Parâmetros Curriculares Nacionais: Geografia e Historia. Brasília - DF. 1997

SECRETARIA DE EDUCAÇAO FUNDAMENTAL. Parâmetros Curriculares Nacionais: Geografia. Brasília, 2001.

VESENTINI, José Willian, Realidades e Perspectivas do Ensino de Geografia no Brasil. O ensino de Geografia no século XXI, Campinas SP, p. 219-248, 2004.

SP, Plêiade, 2009.

José William, Repensando a geografia escolar para o século XXI, São Paulo - 